\title{
Dare to Play
}

Murmurations:

Journal of

Transformative

Systemic

Practice

\section{Joanna Michopoulou}

\section{Volume 2}

\section{Issue 2}

\section{Winter 2019}

\section{Keywords:}

play,

improvisation,

joint action,

spontaneity,

relational learning,

with-ness

\section{Citation Link}

\section{Abstract}

Inspired by watching a group of children playing freely during their summer holidays, I draw parallels in this essay between the activities of playing and improvisation on the one hand with learning and participatory action in our relational contexts on the other. I offer examples of how I see play as improvisational participatory activity, a key to relational learning, development and growth. With reference to the four stages of competence model, I discuss how "mathematising" expert knowledge, competence evaluation measures and de-contextualised accounting systems, may weaken our abilities for intuitive, spontaneous improvisations in our relational activities, restrict relational learning from within the moment of doing and hold back the development of practice knowledge.

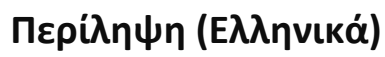

Е $\mu \pi v \varepsilon \cup \sigma \mu \varepsilon \dot{v} \eta$ a



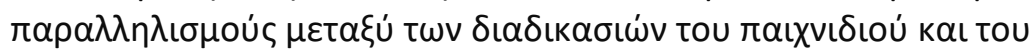

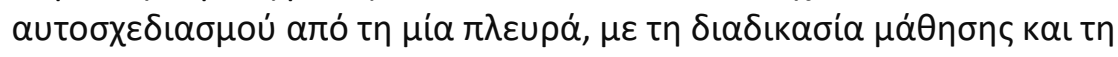

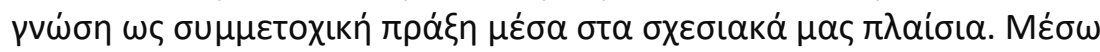

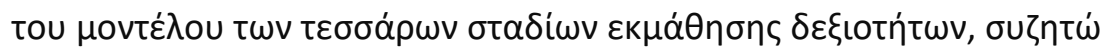



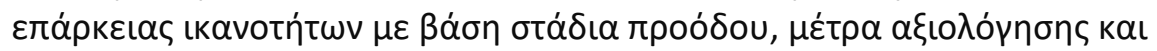

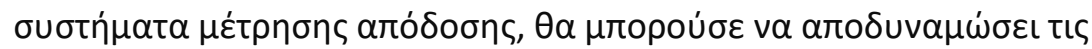

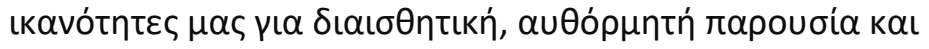

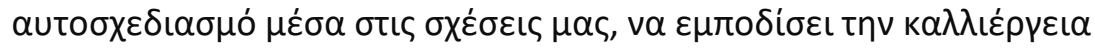






And if I forget him, I may become like the grown-ups who are no longer interested in anything but figures... It is for that purpose, again, that I have bought a box of paints and some pencils. It is hard to take up drawing again at my age, when I have never made any pictures except those of the boa constrictor from the outside and the boa constrictor from the inside, since I was six. I shall certainly try to make my portraits as true to life as possible. But I am not at all sure of success. One drawing goes along all right, and another has no resemblance to its subject. I make some errors too.

De Saint-Exupéry, 1997, p.24. [1943]

(My translation from Greek to English)

\begin{abstract}
Play has the tendency to be beautiful and it maybe that its aesthetic factor is identical with the impulse to create orderly form... The words we use to denote the elements of play belong for the most part to aesthetics, terms with which we try to describe the effects of beauty: tension, poise, balance, contrast, variation, solution, resolution, etc. Play casts a spell over us; it is "enchanting", "captivating".
\end{abstract}

Huizinga, 1950, p.10

\title{
Observing play
}

A couple of years ago, during my summer holidays, I found myself in a position of witnessing children playing freely together in the central square of Cephalonia island in Greece, evening after evening, during the August holiday period. Watching them playing together brought live for me what Shotter calls a "felt knowing that shows up in our readinesses to respond in certain ways, spontaneously..." (Storch \& Shotter, 2013) and I have decided to write about this experience because I was inspired by the way the children were doing their "joint action" (Shotter 2011, p.58) moment by moment. As a systemic therapist I find invaluable whatever can teach me practical lessons about spontaneously responsive relational activity and the experience of watching these children playing made me want to reflect on my way of improvising spontaneous expressive-responsive actions in my relational encounters in my work as a systemic practitioner.

It is not my aim here to idealise the spontaneity, risk taking and collaborative abilities of that specific group of 7-10 year old children and it is not my intention to argue that free playing always works smoothly - as in the example I am going to write about here. But I was struck by the seriousness with which these children have been living their play-time; they really meant business! The moment-bymoment fashion these children were moving together without having pre-planned some schedule of activities and the ease with which they were participating in the fluidity of their play was really fascinating. But what I found most striking when observing these children playing and when talking with them, was the persistency and genuineness with which they were "working" towards something unknown and unplanned which they sincerely considered important: their playing together. 
To our way of thinking, play is the direct opposite of seriousness. We can say: play is not seriousness. But apart from the fact that this proposition tells us nothing about the positive qualities of play, it is extraordinarily easy to refute. As soon as we proceed from "Play is not seriousness" to "play is not serious", the contrast leaves us in the lurch - for some play can be very serious indeed.

Huizinga, 1950, p.5

According to the dictionary, play is engaging in activity for enjoyment and recreation rather than serious or practical purposes. Often characterising something as "play", among grown-ups, means of inferior quality compared to the standards of serious or professional work; but the fact that playing is taking place for enjoyment, does not mean that the processes involved in playing are not serious or high quality processes. One of my favourite quotes by Nietzsche tells us that the maturity of man means to have reacquired the seriousness that one had as a child at play. The way I understand this quote is that for someone to have reached maturity - that is to have reached the most advanced stage in a process - one need to have regressed to the state of a playing child; such is the seriousness and keenness with which children are involved in moment by moment improvisational playing.

In our professional worlds, an unfamiliar and unpredictable situation is often unwanted, it can feel uncomfortable or it may even be looked at with suspicion. Classifying any situation under known categories and normative understandings quickly help us to gain control in some way, but in this way deviations from norms and expectations cannot be dealt with as opportunities for something new to emerge and develop. I remember when I decided to change sector, from finance to psychotherapy, when I was 35 years old, my experience of leaving what I knew and was developed in, in order to dive into the unknown and become a disciple all over again, was powerful; anxiety provoking but amazingly reviving and rewarding. I don't think I would have ever made that change if I didn't have the excitement, eagerness and experimental appetite.

Play is improvisation and improvisation is playing. Jazz musicians improvise; they play together. In jam sessions players interact with other players and make music in a freewheeling environment, without having to be concerned about specific purposes or about pleasing an audience with particular types of deliverables. Improvisations are adventurous and playful attempts to reproduce learned behaviours, adapting them real time to the demands of the current situation. Improvisation may involve copying or "mirroring" while in motion and discovering as you go ad hoc ways to adjust, adapt or transform, in a fitting way to what is going on right in that moment. Composing music might be $a$ purpose of a group of jazz musicians playing together as is finding a child in the hide and seek game between children. But playing is not simply a purpose oriented or a rule-guided activity. It is equally a dynamic rule-making activity. The "mobility agent" in playing together is (re)creational - quite often is the interaction itself - and the how remains to a large extend experimental and adventurous- there is no score in jazz improvisation. Relational interactions in systemic therapy practice are highly improvisational; there is never a fixed score and performativity, as Barad sees it, is more like iterative intra-activity. Goldman (2010) defined improvisation as an embodied performance of self-readiness.

... but what they [jazz musicians] don't do if they want to prosper in the art form is censure each other for the mistakes they make. Instead jazz players learn to approach errors as if they are simply another suggestion for ways to proceed. They might repeat the mistake, amplify it and develop it further until it becomes a new pattern.

Barrett, 2012, p.43 
Being deeply and passionately involved with a situation one meets with for the first time, with flexible purpose and uncertain outcomes - like children meet for the first time with so many new things through playing - I think needs serious seriousness and certainly, if we understand "seriousness" as a state of being present, focused, determined and really interested in whatever it is we are doing, we could say that "seriousness" is an important element of quality and competence. Is children's capacity for serious playing about their intense need to learn and grow? Is it about their capacity for experimenting with unknown things? Is it about their humbleness; the nerve to learn through copying, and insistence in trying to learn despite making mistakes? Is it about their natural trust in living processes?

\section{How far can systemic wisdom go?}

The element of tension in play plays a particularly important part. Tension marks uncertainty, chanciness; a striving to decide the issue and so end it. Baby reaching for the toy, pussy patting a bobbin, a little girl paying ball - all want to achieve something difficult, to success to end a tension. Play is tense.

Huizinga, 1950, p.11

That summer, I discovered that the game of "secret agents" and trying to uncover "mysteries" is one of children's favourite between the ages of 7-10. Many things were fascinating about how children were playing this game but what struck me the most when watching them play, was how the distinction between a "mysterious" situation existing and imagining that a mystery exists was unclear in their minds in the beginning of a game. Anything was potentially a mystery! Anything was potentially a wonder. And it was through their interaction that the "truth" of the matter was becoming clear; it was their performative actions which was bringing their "reality" into being. One evening the children had noticed that one particular stray dog that was coming every evening in the square hadn't appeared for three days. And that was enough for them to set up a co-ordinated investigation, which resulted in finding out that that dog had been ill and mobilising the adults in the square to take the dog to the vet.

But there is really no scientific or other method by which men can steer safely between the opposite dangers of believing too little or of believing too much. To face such dangers is apparently our duty, and to hit the right channel between them is the measure of our wisdom as men.

James 1912, preface

During their play time, the children were showing a great ability to embrace ambiguity. All "what is what" definitions were processed within the group on the spot: what is happening, roles, clues, decisions. Knowing about the doing was not needed in advance; it was coming from within the doing, in the moment of the doing. The mobility agent was the excitement of a joint creation of new activities as they were all moving around a newly formed reality of being secret agents together. Like in Klee's quote: "An active line on a walk moving freely without a goal. Walk for a walk's sake. The mobility agent is the point shifting its position forward." (1968, p.16) 
Figure 1

Extract from Paul Klee pedagogical sketchbook
Two secondary lines, moving around an imaginary main line (Fig. 5):
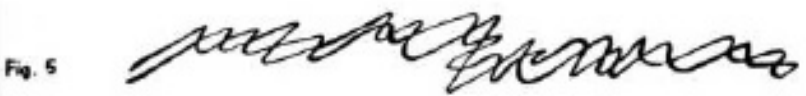

"In our group of secret agents, we are not looking for something, but we are just looking until we find what to look for", an 8 year old child explained when I asked about the game. This made me think of Zen master Suzuki's saying that the mind of the beginner is full of possibilities, whereas in the mind of the expert there are only a few. It is interesting what kinds of questions a child could ask an adult. This is a dialogue with my eight year old daughter one day that summer, after she had finished playing with the children.

- Look here mum! Let me show you the clues we have found! This little piece of cable and this screw and this piece of broken glass, and listen to this Mum, in the pavement outside Mary's house there is a very strange mark, like a hand pointing towards the old library building... I am sure there is something suspicious going on!

- Wow!

- Mum...can you buy me a book?

- Yes, what do you have in mind?

- It'll be a book a bit like a dictionary where I can search and see for example, if I find a screw in the street, what that may mean? Someone may be in danger or something?? If I find a piece of broken glass, what that may be? Maybe it means there was an accident?? As a secret agent mum, how do I know that a clue is a clue?

- How have you been doing it all these days, without a book?

- If someone finds something interesting, we show it to the others and we decide together.

Children sometimes see things clearly that are indeed obscured in later life. We often forget the wonder that we felt as children when the cares of the activities of the "real world" have begun to settle upon our shoulders. Children are not afraid to pose basic questions that may embarrass us, as adults, to ask.

Penrose, 1989, p.580

\section{This place is not known from the outside}

The knowing from within the doing is only known to the knower in the moment of the doing. This moment is of this moment; "this place" is not known from the outside. Spontaneity within the flowing phenomenon of playing together was the main characteristic of those interactions in the main square of Cephalonia. All possibilities were open: the group composition was flexible, the members of the secret agent group were increasing every day, the ages didn't matter, the roles were interchangeable and decisions were being made momentarily in the group. It was as if the playing itself was teaching the children the rules of playing together. Nothing resembled a step by step process, no after-the-fact explanation could possibly account for what was going on. Everything was fluid and emerging. 
... through our advances, we participate in bringing forth the world in its specificity, including ourselves. We have to meet the universe halfway, to move toward what may come to be in ways that are accountable for our part in the world's differential becoming. All real living is meeting. And each meeting matters.

Barad 2007, p.353

Established friendships and new friendships, local children and children who had come to the island for their holidays, children experienced in a game and newcomers to the game, older and younger children, beginners and "experts", all of these distinctions would only occur in my, the observer's, mind. For them, in their playing moments, it just didn't seem to make a difference "what is what" because what seemed to be important was their participation in joint action. Unexpected situations would occur every day; someone would propose a new game, a new child would want to join the group, the leader will be missing one day and someone else will take her role, a child would have to leave early, some child's best friend will not appear one evening, the shy child will be invited to join the group and so on. I know that my way of describing what I was seeing is not going to do justice to what was going on from within those interactions but I will try. So what I thought I was seeing was:

- eagerness to be together and excitement to meet with new things

- openness - experimental mood - intense curiosity

- trusting - believing that this will be safe and it will be fun

- generosity - easy going attitude, forgive, forget, try again

- acceptance of the other way - all points of view were valid, but not imposed

A play community generally tends to become permanent even after the game is over. Of course not every game of marbles or every bridge-party leads to founding a club. But the feeling of being "apart together" is an exceptional situation of sharing something important, of mutually withdrawing from the rest of the world and rejecting the usual norms, retains its magic beyond the duration of the individual game.

Huizinga, 1950, p.12

According to Barad, "things" don't pre-exist they are agentially enacted and become determinately bounded and propertied within phenomena. Outside of particular agential intra-actions, "words" and "things" are indeterminate." (2007, p.150). Our natural ways of going on together, which in the grownups' book of reference we call coordination and collaboration, was something which the children appeared to be doing with ease and success, moment by moment, spontaneously. For us, who have learned to subject our doings to intellectual and volitional examinations, the concept of collaboration, for example, can be deliberately broken down to certain distinguishable elements which we can then teach, measure, excel on using and apply when needed: active and empathic listening, reflexivity to help us evaluate our position in a broader context, an ability to move between different points of view and an appreciation of multiplicity, an ability to participate in a co-creation of shared contexts and a flexibility to move positions. But adding together distinguishable elements cannot help us understand and experience that which we are trying to produce or re-create. We need to start with our 
spontaneous participation in unique living situations in order to move away from seeing samenessmaybe with small variations - in order for the novel and unique not to keep getting away from us.

Dare to grope around, dare to be tentative to hesitate, to try different ways of expressing the 'it' that seems to be 'there', awaiting our further creative development of it within our lives together. Dare to creatively stumble around in words.

Shotter, 2011, p.220

I have to say that I felt humbled as a systemic practitioner, witnessing the level of plasticity, movability, curiosity, openness and spontaneity of those children playing together. And I have thought that there isn't perhaps a better example of what Shotter (2011) calls "imaginative, exploratory thought" (p.2), "with-ness thinking" (p.2) and "spontaneously responsive bodily activity" (p.4). As a therapist I feel I must keep asking myself whether while in motion, in uniquely occurring interactions with clients, I manage to stay in motion; or whether it may happen sometimes in my professional doings to withdraw from my ongoing practical activities with the other who is standing in front of me, and position myself as static, theoretical thinker; I need to keep asking myself if the forms of life offered by theories are useful, what is their usefulness and for whom. In professional practice there are systematic orders of connecting with our clients which are working in a representational manner and involving specific meanings around various ways of being with the clients. Standardising modes and professional beliefs, which we value and understand, are in place. But in participatory, relational time-space, as Shotter puts it we need to keep moving from "understanding" to "coming to an understanding" (McNamee, 2016, p.94), real time, together with the other.

\section{A competent player?}

The urge to be first has as many forms of expression as society offers opportunities for it... but in whatever shape it comes, it is always play. The astonishing similarity that characterizes agonistic customs in all cultures is perhaps nowhere more striking than in the domain of human mind itself, that is to say, in knowledge and wisdom

Huizinga, 1950, p.105

Recently, I came across again the four stages of competence learning model in psychology. In our world, competencies are what people need in order to be successful in their lives and jobs, so competence is a word packed with a lot of importance. The model made me think about the idea that people must always have ways to ensure outcomes and control of their actions. In our professional environments, we demonstrate our competencies and we provide evidence for our performance based on measurable outcomes. Mechanisms of control demand proofs that we know what we are doing and that we are doing what we already know; what we are getting involved with has to be explained in terms of the knowledge and expertise we already have acquired. I wondered how much of our embodied knowings and living skills can actually be measurable in terms of scales and tables and what might the effect of measuring everything, be, on our on-going learning, and spontaneity? 
How encouraged do we feel in our professional worlds to keep "stumbling around in words" (Shotter, 2011, p.220).

Of course, the four stages of competence model is just a model - not a systemic model - and as a model it looks at things in specific ways, it serves specific purposes and aims at specific uses. It also measures specific things; in this case, it measures skills, abilities and expertise. But I got interested in discussing the concept of competence in this paper because competence, like maturity, is supposed to be a characteristic of someone who has reached an advanced level in a development process and, to go back to Nietzsche's idea that maturity go hand in hand with our ability for serious playing.

So, the model tells us about the psychological states involved in the process of progressing from incompetence to competence in a skill. According to the model as we start learning a new skill, we pass through four stages: the stage of unconscious incompetence, where our intuition is wrong, the stage of conscious incompetence where our analysis is wrong, the stage of conscious competence when our analysis is right and finally the stage of our unconscious competence where our intuition is right. Well, it makes sense. But a side understanding is that spontaneity and correctness can only coexist then in the last stage of learning and applying a skill.

Must spontaneity be a privilege of expertise? And must everybody else, the "non-experts", only act after careful thinking? It can get very confusing if we try to separate experience and competence from knowing and intuition. When we are acting spontaneously, we are spontaneously focusing on some things while blocking out other things. And when we are thinking carefully about acting, we are again focusing on some things and deciding to block others. And in our moments of interaction with people, we need to be able to move between the two constantly. "...there is some believing tendency wherever there is willingness to act at all. (James, 1912, preface).

Figure 2: The four stages of competence model (based on Curtis \& Warren, 1973)

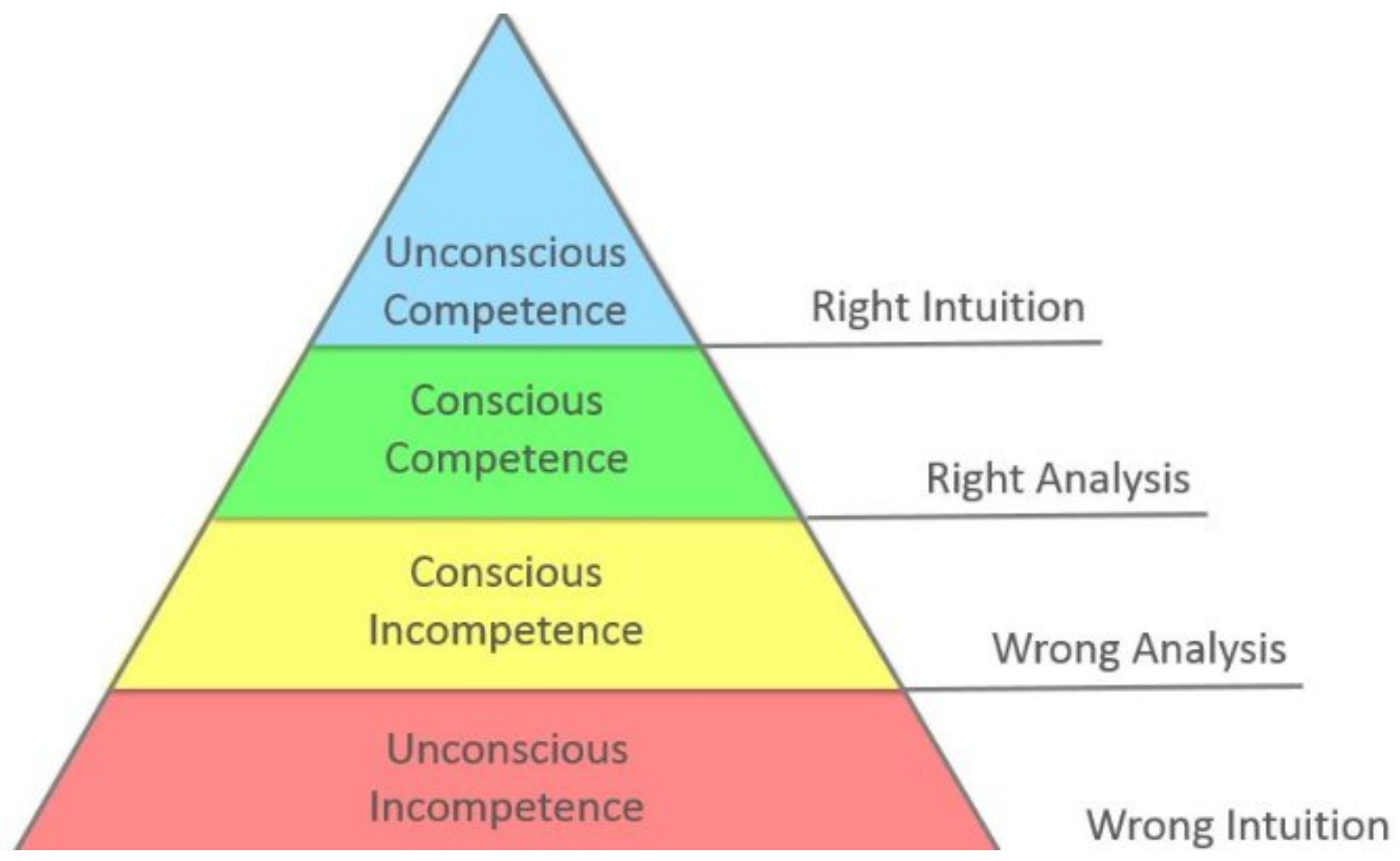


Let me go back to the children playing for a moment. One evening, I happened to overhear a brief dialogue which took place between an older and a younger child who had just met in the square.

- Can you skateboard?

- Yes.

The older one is the owner of a skateboard. The younger one is looking at the board so the owner of the board is asking the little one if she knows how to skateboard. The little one who had never tried skateboarding before replied "yes"; and that wasn't a lie. Off she jumped on the board and started riding. The practical outcome - because as a grownup, I couldn't stop thinking about outcomes and consequences - I couldn't have predicted: of course she was slow and her balance wasn't good; but she was actually doing it, she was skateboarding. Although I knew she had never ridden a skateboard before and no doubt my answer to the skateboard's owner would have been "no, she can't skateboard", at that moment I just wasn't sure what I knew; a new knowledge was emerging from within the moment. Was she competent? Depends really on what one compares with, what is the measure, and what is the context. One thing I can say: to be(come) a competent skateboarder one has to be competent in daring to take the risk of potential falls and failures.

\section{Always a beginning}

Greek knowledge and Greek science were not products of the school as we understand it. That is to say, they were not the by-products of an educational system designed to train the citizen for useful and profitable purposes. For the Greek, the treasures of the mind were the fruits of leisure - $\sigma \chi 0 \lambda \eta \dot{~-~ T h e ~ w o r d ~ " s c h o o l " ~(~} \sigma \chi 0 \lambda \eta \dot{)}$ has a curious history behind it. Meaning originally leisure, it has now acquired precisely the opposite sense of systematic work and training, as civilisation restricted the free disposal of the young man's time more and more and herded larger and larger classes of the young to a daily life of severe application from childhood onwards.

Huizinga, 1950, p.148

The four stages of consciousness learning model tells us about the value of acquiring experience in a skill and the link between expertise, intuitive action and good performance - but it doesn't tell us about the impact that being open to the fluid possibilities of becoming can have on acting in-themoment. Although there is no doubt that the more experienced and familiar one is with whatever one is doing, the more confident one will be in doing it and the freer he or she will feel to act spontaneously and to take risks in the moment of action, with living forms, I believe this is a dangerous link to hold on to, because of what it can imply for beginners, and for whoever is involved with continuous beginnings, new encounters and emerging realities, as therapists are in relational practice. In the midst of the fluid complexity of relating, in our unique, as if for the first-time encounters with the other, we never stop learning, and our competence is not something which we reach ones and for all. In certain ways we are always beginners and open to new learnings. This is part of our ethical stance; we follow messy processes; every day we bump into moments when we will not know how to go on. Edward Teller in Life magazine quoted Niels Bohr as being "an expert is someone who has made all the mistakes which can be made in a narrow field" (Coughlan, September 1954, p.62). But of course, 
relating with the other is far from a narrow and definite field; and "all the mistakes" is not a realistic possibility.

There is a lot a beginner doesn't know and she will be finding out in a continuous learning process. But in the worlds we are co-creating with one another, in our training programmes, in our professional environments, if we believe in the immense value of expertise and competence and if we see competence as a de-contextualised ability, if we believe that our skills and expertise must necessarily come before spontaneous doings, if we believe that our intuition and analysis are wrong until we become competent - at which point we will be able to act spontaneously because we will be right how are we going to open up to the messiness of relational moments? How vulnerable will we be in front of any new learning which will be popping up from within our relational encounters? There is a quote from Maria Rilke which I like and which plays with the distinction between the concept of a beginner and someone with experience: "There are no classes in life for beginners; right away you are always asked to deal with what is most difficult".

Everything we have learned formally and informally will make their way into our intuitive understandings about the situation we are in this moment but in our spontaneous actions, in our expressive responsive in-the-moment doings, there is much more than the past shapes of what we have already learned and experienced. What we come to know right in this moment, maybe we never knew before and maybe we never encounter in the future again.

Our paths to acquired knowledge do not follow an exact design but we learn in the course of the making process, in our interactions with unforeseen conditions every time. And during these times, we are not "competent" experts but neither we are not necessarily wrong in our spontaneity, as the competence model suggests. The kind of practising through which we actually learn and develop is only done in practice, unconsciously and spontaneously. It is the specific, the unique circumstances, the others around us who will call out of us, our spontaneous responses in variable repetition (Shotter, 2011, p.17), again and again. If learning is something that happens incidentally and effortlessly in participatory contexts (Shotter, 2011, p.96), how can we appreciate and relax into this process when we have learned that our spontaneous responsivities will be wrong? How can spontaneity survive our self-conscious, effortful attention to avoid mistakes?

My eyes already touch the sunny hill. going far ahead of the road I have begun.

So we are grasped by what we cannot grasp;

it has inner light, even from a distance-

and charges us, even if we do not reach it, into something else, which, hardly sensing it, we already are; a gesture waves us on answering our own wave...

but what we feel is the wind in our faces. 


\section{References}

Barad, Karen (2007). Meeting the Universe Halfway. Quantum Physics and The Entanglements of Matter and Meaning. Durham, NH: Duke University Press

Barrett, Frank (2012). Say Yes to The Mess. Surprising Leadership Lessons from Jazz. Boston, MA: Harvard Business Review Press.

Coughlan, Robert (1954). Dr. Edward Teller's Magnificent Obsession. In LIFE magazine. $6^{\text {th }}$ September 1954.

Curtiss, Paul R.\& Warren, Phillip W. (Eds.) (1973). The dynamics of life skills coaching. Life skills series. Prince Albert, Saskatchewan: Training Research and Development Station, Dept. of Manpower and Immigration. OCLC 4489629



Goldman, Daniel (2010). I Want to be Ready. Improvised dance as a practice of freedom. Ann Arbor, MI: University of Michigan Press.

Huizinga, Johan (1950). Homo Ludens: a Study of the Play Element in Culture. New York, NY: Roy Publishers.

James, William (1912 [1897]). The Will to Believe and Other Essays in Popular Philosophy. London: Longmans, Green \& Co.

Klee, Paul (1968). Pedagogical Sketchbook. New York, NY: Praeger Publishers.

http://ing.univaq.it/continenza/Corso\%20di\%20Disegno\%20dell\%27Architettura\%202/TESTI\%20D\%27AUTORE /Paul-klee-Pedagogical-Sketchbook.pdf

Maria Rilke, Rainer (1924). A Walk. In Uncollected Poems. Translated by Edward Snow. Bilingual Edition. Farrar, Straus and Giroux.

McNamee, Sheila (2016). The Ethics of Relational Process John Shotter's Radical Presence. In Joint Action Essays in honour of John Shotter. Corcoran, Tim \& Cromby, John (Eds). London: Taylor and Francis.

Penrose, Roger (1989). The Emperor's New Mind Concerning Computers Minds and the Laws of Physics. Oxford: Oxford University Press.

Shotter, John (2011). Getting it: With-ness Thinking and the Dialogical... In Practice. New York: The Hampton Press Communication Series.

Storch, Jacob \& Shotter, John (2013). 'Good Enough', 'Imperfect', or Situated Leadership:

Developing and Sustaining Poised Resourcefulness within an Organization of Practitioner-Consultants, International Journal of Collaborative Practice 4, 1, 1-19.

\section{Author}

Joanna Michopoulou is a systemic therapist in private practice based in Athens. Since 2011, when Joanna moved back to Greece after having lived in the UK for 15 years, she has been working collaboratively with individuals, couples and families and have been running personal development groups and workshops. Her Professional Doctorate in Systemic Practice research is on Improvisational Movements as Relational Responsivity.

Email: jmichopoulou@googlemail.com

\section{Citation}

Michopoulou, Joanna (2019). Dare to Play. Murmurations: Journal of Transformative Systemic Practice, 2, 2, 18-28. https://doi.org/10.28963/2.2.3 